\title{
Autosomal recessive spastic ataxia of Charlevoix-Saguenay: a family report from South Brazil
}

\author{
Ataxia espástica autossômica recessiva de Charlevoix-Saguenay: relato de uma família do \\ sul do Brasil \\ Daniela Burguêz, , Camila Maria de Oliveira1, Marcio Aloísio Bezerra Cavalcanti Rockenbach³, \\ Helena Fussiger ${ }^{1}$, Leonardo Modesti Vedolin,4, Pablo Brea Winckler ${ }^{5}$, Marcelo Krieger Maestri6, \\ Alessandro Finkelsztejn ${ }^{5}$, Filippo Maria Santorelli7, Laura Bannach Jardim,2,8,4, Jonas Alex Morales Saute
}

\begin{abstract}
Autosomal recessive spastic ataxia of Charlevoix-Saguenay (ARSACS) is an early-onset, neurodegenerative disorder caused by mutations in SACS, firstly reported in Quebec, Canada. The disorder is typically characterized by childhood onset ataxia, spasticity, neuropathy and retinal hypermyelination. The clinical picture of patients born outside Quebec, however, is often atypical. In the present article, the authors describe clinical and neuroradiological findings that raised the suspicion of an ARSACS diagnosis in two female cousins with Germanic background from Rio Grande do Sul, Brazil. We present a review on the neuroimaging, ophthalmologic and neurophysiologic clues for ARSACS diagnosis. The early-onset, slowly progressive, spastic-ataxia phenotype of reported patients was similar to ARSACS patients from Quebec. The SACS sequencing revealed the novel homozygous c.5150_5151 insA frameshift mutation confirming the ARSACS diagnosis. ARSACS is a frequent cause of early onset ataxia/spastic-ataxia worldwide, with unknown frequency in Brazil.
\end{abstract}

Keywords: cerebellar ataxia; spastic paraparesis; genetics; magnetic resonance imaging; ophthalmology.

\section{RESUMO}

A ataxia espástica autossômica recessiva de Charlevoix-Saguenay (ARSACS) é uma doença neurodegenerativa de início precoce causada por mutações no gene SACS que foi inicialmente descrita na região de Quebec, Canadá. A apresentação típica de ARSACS é caracterizada por ataxia, espasticidade, polineuropatia e hipermielinização das fibras nervosas da retina de início infantil. No presente artigo, descrevemos os achados clínicos e neurorradiológicos que levaram à suspeita de ARSACS em duas primas descendentes de alemães naturais do Rio Grande do Sul, Brasil e revisamos os achados de neuroimagem, oftalmológicos e neurofisiológicos de ARSACS. O fenótipo de ataxia-espástica de início infantil precoce apresentado pelas pacientes era similar ao classicamente descrito em Quebec. O sequenciamento do SACS revelou a mutação nova c.5150_5151 insA (mudança na matriz de leitura), em homozigose, confirmando o diagnóstico de ARSACS. A ARSACS é uma causa frequente de ataxia/ataxia-espástica de início precoce mundialmente, entretanto sua frequência é desconhecida no Brasil.

Palavras-chave: ataxia cerebelar; paraparesia espástica; genética; imagem por ressonância magnética; oftalmologia.

Autosomal recessive spastic ataxia of Charlevoix-Saguenay (ARSACS) was initially reported in the Charlevoix-Saguenay region of northeastern Quebec, Canada, in 1978, as an early-onset, neurodegenerative disorder ${ }^{1,2}$. The ARSACS is caused by bi-allelic mutations in SACS (chromosome 13q12.12) that encode sacsin; a protein highly expressed in large neurons, including cerebellar

${ }^{1}$ Hospital de Clínicas de Porto Alegre, Serviço de Genética Médica, Porto Alegre RS, Brasil;

${ }^{2}$ Hospital de Clínicas de Porto Alegre, Laboratório de Identificação Genética, Porto Alegre RS, Brasil;

${ }^{3}$ Hospital de Clínicas de Porto Alegre, Serviço de Radiologia, Porto Alegre RS, Brasil;

${ }^{4}$ Universidade Federal do Rio Grande do Sul, Departamento de Medicina Interna, Porto Alegre RS, Brasil.

${ }^{5}$ Hospital de Clínicas de Porto Alegre, Serviço de Neurologia, Porto Alegre RS, Brasil;

${ }^{6}$ Hospital de Clínicas de Porto Alegre, Serviço de Oftalmologia, Porto Alegre RS, Brasil;

${ }^{7}$ Molecular Medicine-Neurogenetics, IRCCS-Fondazione Stella Maris, Pisa, Italy;

${ }^{8}$ Universidade Federal do Rio Grande do Sul, Programa de Pós-Graduação em Medicina: Ciências Médicas, Porto Alegre RS, Brasil.

Correspondence: Jonas Alex Morales Saute; Hospital de Clínicas de Porto Alegre; Rua Ramiro Barcelos, 2350; 90035 -903 Porto Alegre RS, Brasil;

E-mail: jsaute@hcpa.edu.br

Conflict of interest: There is no conflict of interest to declare.

Received 08 November 2016; Accepted 14 February 2017. 
Purkinje cells. Sacsin contains a DNAJ motif, two domains similar to the N-terminal of the HSP90 class of heat-shock protein and a ubiquitin-like domain, that is probably involved in the ubiquitin-proteasome system and chaperone-mediated protein folding $3,4,5,6$.

In Quebec, ARSACS was described as a homogenous syndrome with childhood onset, between 12 and 18 months of age, typically characterized by slowly progressive signs such as spastic-ataxia of upper and lower limbs, dysarthria, slurred and dysrhythmic speech, distal amyotrophy and absence of ankle reflexes after 25 years of age. Furthermore, early non-progressive signs were also reported, including generalized hyperreflexia, Babinski sign, broken-up ocular smooth pursuit and retinal hypermyelination ${ }^{2}$. Now, ARSACS has been described worldwide; however, the clinical picture of patients born outside Quebec is often different, including atypical findings such as later onset, cognitive impairment, ophthalmoplegia and absence of spasticity and retinal hypermyelination ${ }^{7,8,9,10,11,12,13,14,15}$. Nerve conduction studies generally demonstrate signs of progressive axonal-demyelinating peripheral neuropathy and magnetic resonance imaging (MRI) shows predominant superior cerebellar vermis atrophy ${ }^{2}$ and T2-fluid-attenuated inversion recovery (FLAIR) pontine linear hypointensities ${ }^{16,17}$.

We aimed to report clinical, imaging and molecular findings of a Brazilian family in which two cousins presented with a similar phenotype to ARSACS families from Quebec.

\section{METHODS}

\section{Case report study}

Two cousins were referred to a neurogenetics outpatient service to investigate a clinical picture of ataxia. They were included in an ataxia screening panel from the Brazilian institution, after a written informed consent form was obtained. The present work was approved by the Ethics Committee from the institution at which the work was performed - Comissão de Ética em Pesquisa do Hospital de Clínicas de Porto Alegre, which follows the Code of Ethics of the World Medical Association (Declaration of Helsinki) and the standards established by the author's Institutional Review Board and granting agency.

After excluding other causes of hereditary ataxia, the coding region and exon-intron boundaries of the nine coding exons of SACS (NM_014363.5) were sequenced (Molecular Medicine-Neurogenetics, Pisa, Italy), amplified by polymerase chain reaction. Amplicons were sequenced in both directions using a standard Sanger sequencing approach on an ABI3130xl automatic sequencer.

All patients and their parents gave written informed consent to publish this report and its media files.

\section{Patient description}

Both cousins were born to consanguineous parents (Figure 1) and reported multiple other consanguineous marriages in the family. The surname related to consanguinity was of Germanic background. The family lives in the countryside of Camaquã, a city with 63,000 inhabitants, located in Rio Grande do Sul, the southernmost state of Brazil, with mainly Azorean, Germanic and Polish colonization. No other similar cases were reported in their family.

\section{Case 1}

Patient 1 was a 28-year-old woman presenting with an early-onset slowly progressive spastic-ataxic disorder. Disease onset was probably in the first or second year of life, since she achieved independent walking at 20 months of age and never acquired a steady gait. Slurred speech started at the age of 10 and dysphagia was also reported in the following years. On current neurological examination, she presented with a spastic-ataxic gait; abnormal balance; moderate lower limb spasticity; general hyperreflexia, except for absent Achilles reflexes; bilateral Babinski sign; and mild limb ataxia. Other findings were broken-up smooth pursuit and gazeevoked nystagmus, dysarthria, pes cavus and hammertoes. No cognitive deficit was observed.

An MRI showed cerebellar vermis atrophy and T2-FLAIR central pontine linear hypointensities (Figure 2), raising the suspicion of an ARSACS diagnosis. Fundoscopy and optical coherence tomography showed thickening of the nerve fiber retinal layer, compatible with hypermyelination (Figure 3). The electroretinogram was normal and pattern reversal visual evoked potentials were prolonged bilaterally. Nerve conduction studies revealed a length-dependent, predominantly sensory, axonal-demyelinating sensorimotor polyneuropathy. Both upper and lower limb cortical somatosensory evoked potentials were absent.

\section{Case 2}

Patient 2 was a 30-year-old woman also presenting with an early-onset, slowly progressive, spastic-ataxic disorder. She started independent walking at 13 months of age; frequent falls and gait difficulties were noticed at two years of age with progressive worsening thereafter. Progressive distal weakness in her lower limbs started at 15 years of age, resulting in foot drop. Neither significant

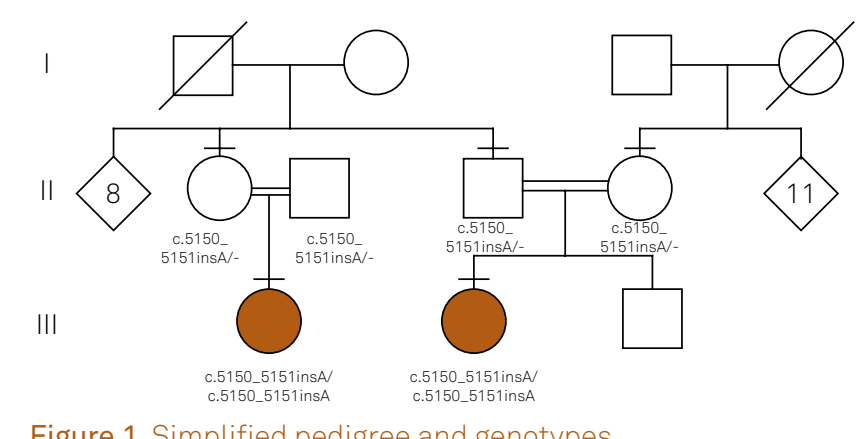

Figure 1. Simplified pedigree and genotypes. 

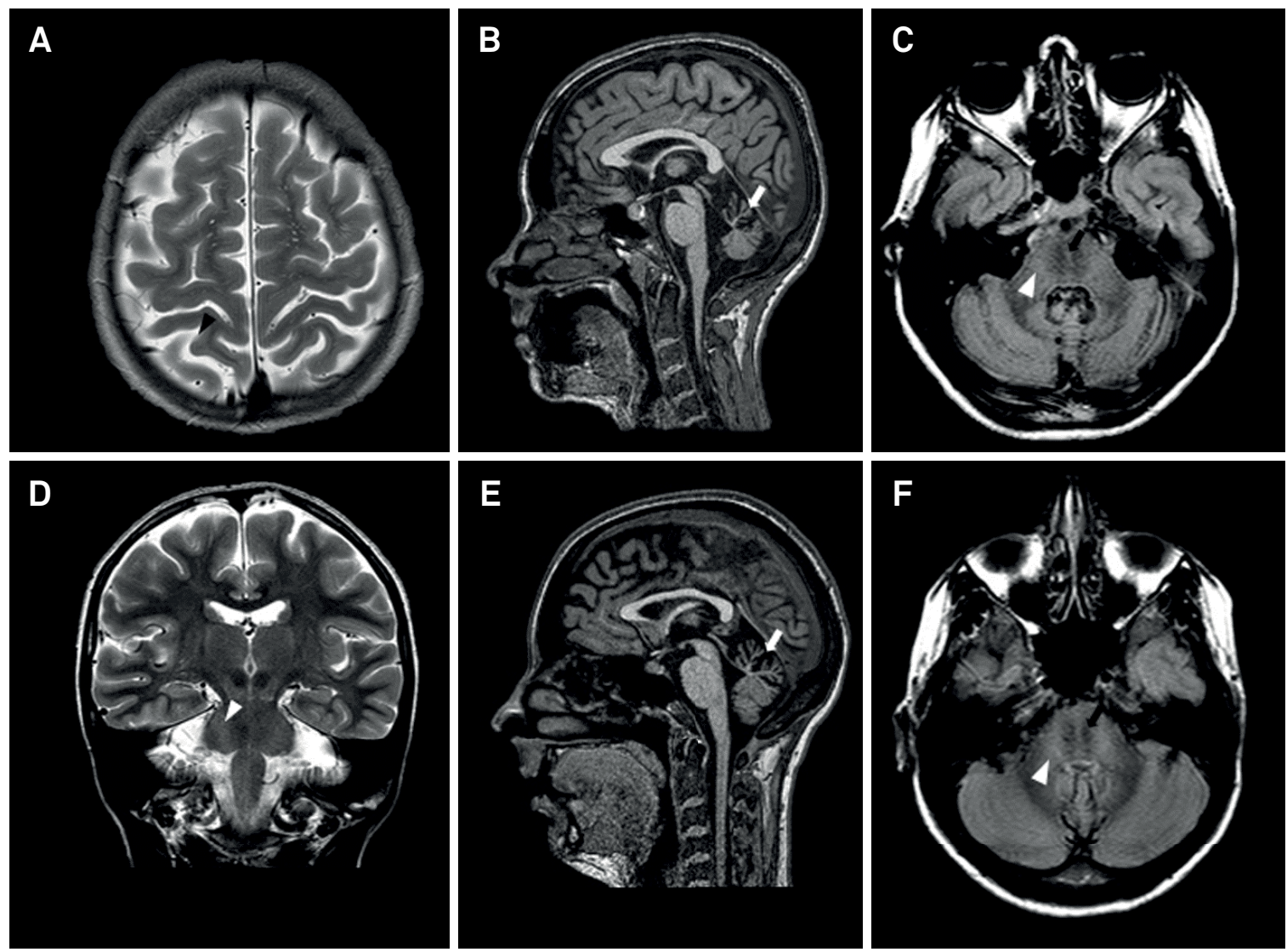

Figure 2. Brain MRI of ARSACS patients. Brain MRI of patient 1 (A-D) and patient 2 (E-F). A) Axial T2-weighted image showing mild parietal lobe atrophy (black arrowhead); B) sagittal T1-weighted image showing superior cerebellar vermian atrophy (white arrow); C) axial T2FLAIR weighted image showing linear hypointensities in the pons (black arrows) and hyperintensities of the lateral pons merging into the middle cerebellar peduncles (white arrowhead); D) coronal T2-weighted image showing hyperintensities of the lateral pons merging into the middle cerebellar peduncles (white arrowhead); E) sagittal T1-weighted image showing superior cerebellar vermian atrophy (white arrow); F) axial T2-FLAIR weighted image showing linear hypointensities in the pons (black arrows) and hyperintensities of the lateral pons merging into the middle cerebellar peduncles (white arrowhead). FLAIR, fluid-attenuated inversion recovery.

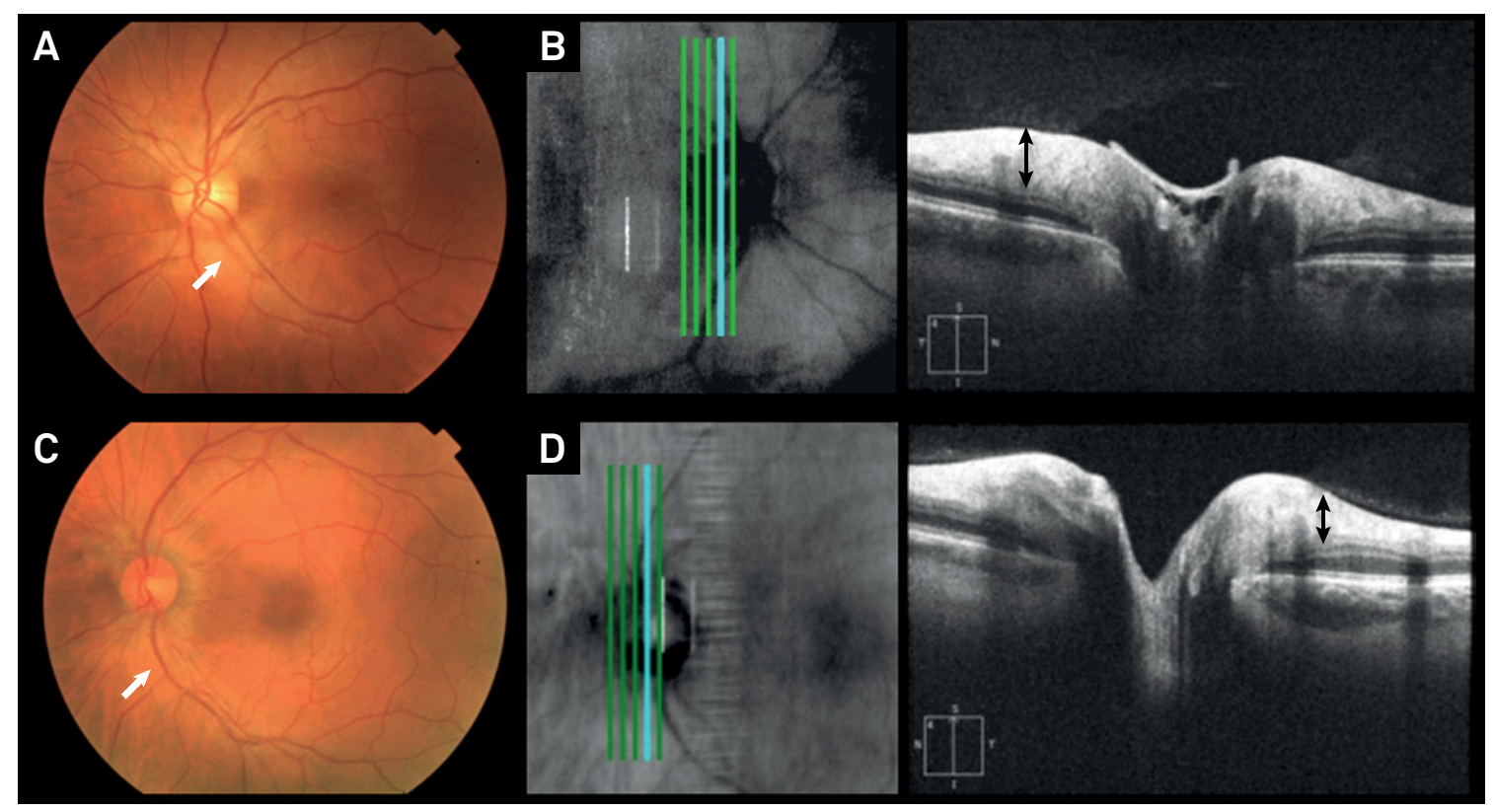

Figure 3. Fundoscopy and optical coherence tomography of ARSACS patients. Ophthalmological evaluation of patient 1 (A-B) and patient 2 (C-D). A) and C) striated whitish aspect of the peripapillar retina suggestive of nerve fiber retinal layer hypermyelination on fundoscopy (white arrow); B) and D) increased thickness and reflectance of the nerve fiber retinal layer (black arrow) on optical coherence tomography. 
dysphagia nor slurred speech were reported. A clinical picture very similar to Patient 1 was seen on neurological examination, with the addition of foot drop. Cognitive function was preserved.

An MRI showed similar findings to Patient 1 (Figure 2). Additionally, tractography with diffusion tensor imaging showed thick and displaced transverse pontine fibers with compressed corticospinal tracts in the pons (Figure 4).

Fundoscopy and optical coherence tomography showed thickening of the nerve fiber retinal layer (Figure 3). Electroretinogram and pattern-reversal visual evoked potentials were normal bilaterally. Nerve conduction studies revealed a length-dependent, predominantly sensory, axonal-demyelinating sensorimotor polyneuropathy. Cortical somatosensory evoked potentials were prolonged in upper, and absent in lower, limbs.

\section{Diagnostic work-up}

An extensive diagnostic work-up for autosomal recessive and dominant ataxic disorders was performed for both cousins. Molecular analysis for Friedreich's ataxia, spinocerebellar ataxias type $1,2,3,6,7,10,12,17$, and dentatorubral-pallidoluysian atrophy were normal. Normal blood levels of vitamin E, LDL and HDL cholesterols, triglycerides, alpha-fetoprotein, lactate, ceruloplasmin and immunoglobulins A, E, G and M; and normal leukocytes activities of arylsulfatase A, hexosaminidase A, galactocerebrosidase, beta-galactosidase and chitotriosidase, were found.

Their clinical pictures were highly suggestive of an autosomal recessive condition. Posterior fossa MRI and ophthalmological findings suggested an ARSACS diagnosis. The SACS sequencing revealed that Patients 1 and 2 were homozygous for the novel frameshift variant c.5151_5152insA, and that both pairs of parents were heterozygous for the variant (Figure 1). This DNA variant was absent from the Exome Aggregation Consortium and from 1000 genomes project databases, and it was classified as pathogenic according to the 2015 American College of Medical Genetics and Genomics criteria ${ }^{18}$, confirming the diagnosis of ARSACS.
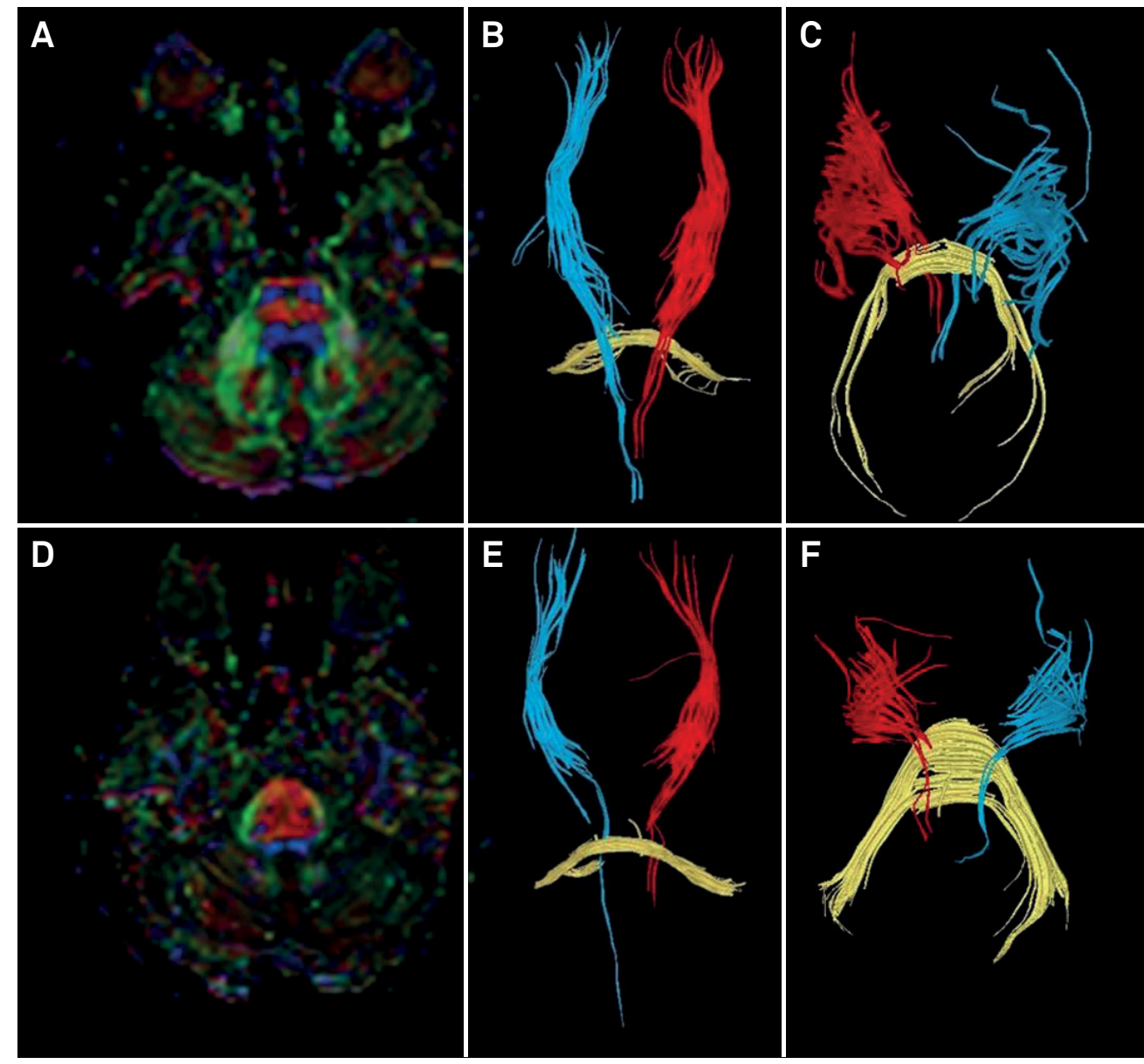

Figure 4. Diffusion tensor imaging tractography in ARSACS. Fractional anisotropy images show the difference between a healthy individual (A-C) and patient 2 with ARSACS (D-F). While the healthy patient (A) has normal sized corticospinal (blue) and pontine transverse (red) tracts, patient 2 (D) has abnormally thickend pontine transverse tracts, leading to displaced and reduced corticospinal tract thickness. Tractography of the corticospinal tract (red and blue) and transverse pontine fibers (yellow) are shown in images $B, C$, E and F. 


\section{DISCUSSION}

Autosomal recessivespasticataxia ofCharlevoix-Saguenay was first described in Quebec province, Canada. The incidence at birth of the disease in the Charlevoix-Saguenay region of Quebec is around 50/100,000 live born infants with a carrier prevalence estimated to be $1 / 22^{7,19}$, but it is largely unknown in other countries. Since the identification of several mutations in many populations, it is now recognized that ARSACS is not only limited to this region, but occurs worldwide $^{8-15}$. More than 100 SACS mutations have been described to date. The majority of Quebecois harbor a homozygous single nucleotide deletion (c.8844delT) due to a founder effect, whereas about $4 \%$ of the total carrier frequency harbor the nonsense c.7504C > T, and additional mutations (including four recurrent alleles) are less common ${ }^{20}$. In a few compound heterozygous patients, this mutation was associated with $(5254 \mathrm{C}>\mathrm{T})$ nonsense mutation ${ }^{3}$.

The presence of certain brain MRI, retinal and nerve conduction abnormalities in ataxic or spastic individuals might raise suspicion of an ARSACS diagnosis ${ }^{17,21,22,23,24,25}$.

\section{Neuroimaging}

At least three case series (64 patients in total) have evaluated qualitative brain MRI findings in ARSACS patients born outside Quebec ${ }^{17,24,25}$. The MRI findings with greater sensitivity for ARSACS diagnosis were predominant superior cerebellar vermis atrophy (range: $88-100 \%$ ), T2-FLAIR pontine linear hypointensities (range: 46-100\%), enlargement of middle cerebellar peduncles (range: 22-100\%) and T2-FLAIR hyperintensities of the lateral pons (range: 17-100\%). As these studies only reported MRI abnormalities in ARSACS patients, it was not possible to estimate the specificity of the findings. However, considering that T2-FLAIR pontine linear hypointensities were rarely described for other diseases, this is probably the most specific MRI sign of ARSACS.

\section{Ophthalmological findings}

Case series and reports have depicted low sensitivity (17-19\%) of prominent myelinated retinal nerve fibers for an ARSACS diagnosis in patients born outside Quebec ${ }^{21,24,25}$, except for a recent Italian study that reported 4/5 ARSACS patients with this finding ${ }^{22}$. Specificity of retinal abnormalities for an ARSACS diagnosis, however, seems to be high, although not adequately addressed up to now. Importantly, some authors point out that ARSACS might be underdiagnosed due to erroneous fundoscopy interpretation as persistent myelination of the retina (present in $1-2 \%$ of normal population) and that optical coherence tomography might help to differentiate this pattern from thickening of peripapillar retinal fibers typical of ARSACS $^{23}$.

\section{Nerve conduction studies}

At least two case series (46 patients evaluated with nerve conduction studies) evaluated peripheral nervous system abnormalities in ARSACS patients born outside Quebec ${ }^{24,25}$. Sensitivity of sensorimotor polyneuropathy ranged from 88-97\%, with axonal involvement in $25 \%$, demyelinating in $53 \%$ and both axonal and demyelinating in $14 \%$ of patients ${ }^{25}$. Therefore, peripheral neuropathy is another sensitive marker for an ARSACS diagnosis. A demyelinating component of the sensorimotor peripheral neuropathy (present in $67-88 \%$ of cases) might help to distinguish ARSACS from other common recessive ataxias like Friedreich's ataxia, POLG or ataxia with oculomotor apraxia type $2^{24}$.

\section{ARSACS frequency worldwide, and in Brazil}

Autosomal recessive spastic ataxia of CharlevoixSaguenay has rarely been addressed in population studies outside Quebec, in the context of autosomal recessive ataxias, spastic ataxias and hereditary spastic paraplegias. The relative frequency of ARSACS varied from $0.3 \%$ of hereditary spastic paraplegia patients to $5 \%$ of early onset ataxia patients from Germany ${ }^{24,26}$; and to $8 \%$ of spastic ataxia or congenital ataxia patients from multiple origins ${ }^{25}$. The ARSACS frequency among ataxic or hereditary spastic paraplegia families from Brazil is unknown.

The two individuals in the present report presented with clinical, neuroimaging, electrophysiological and ophthalmological findings resembling the characteristics of the Quebec patients, which led to the suspicion of ARSACS. Before them, three Brazilian siblings presenting with a clinical diagnosis of typical ARSACS, without molecular confirmation, were reported ${ }^{27}$. Therefore, there is reason to expect other cases, typical or atypical, in our population.

In conclusion, ARSACS is a spastic ataxic disorder, with worldwide distribution, being the second or third most common cause of autosomal recessive ataxias in some series outside Quebec ${ }^{24}$. Brain MRI is a mandatory complementary investigation for ataxic disorders of unknown diagnosis ${ }^{28}$ and ARSACS is one of the diseases where a specific MRI pattern may give rise to a correct diagnosis. Both ophthalmological evaluation and nerve conduction studies should be routinely ordered for patients with ataxia for a better phenotypic characterization. The suspicion of persistent myelination of the retina in an ataxic patient should be confirmed by optical coherence tomography; prominent myelinated retinal nerve fibers on fundoscopy should lead to SACS sequencing. A demyelinating or axonal-demyelinating sensorimotor polyneuropathy in an ataxic patient should also raise ARSACS suspicion. Finally, atypical ARSACS cases with Charcot-Marie-Tooth-like, or other complex phenotypes, might lack both MRI and fundoscopy abnormalities. Their diagnosis may be made with a next-generation sequencing panel or whole exome sequencing analysis ${ }^{24,25}$. 
1. Barbeau A, Bouchard R, Bouchard RW. Autosomal recessive spastic ataxia of Charlevoix-Saguenay. Can J Neurol Sci. 1978;5(1):61-9.

2. Bouchard JP, Richter A, Mathieu J, Brunet D, Hudson TJ, Morgan Ket al. Autosomal recessive spastic ataxia of Charlevoix-Saguenay. Neuromuscul Disord. 1998;8(7):474-9. https://doi.org/10.1016/S0960-8966(98)00055-8

3. Richter A, Rioux JD, Bouchard JP, Mercier J, Mathieu J, Ge B et al. Location score and haplotype analyses of the locus for autosomal recessive spastic ataxia of Charlevoix-Saguenay, in chromosome region 13q11. Am J Hum Genet. 1999;64(3):768-75. https://doi.org/10.1086/302274

4. Engert JC, Doré C, Mercier J, Ge B, Bétard C, Rioux JD et al. Autosomal recessive spastic ataxia of Charlevoix-Saguenay (ARSACS): high-resolution physical and transcript map of the candidate region in chromosome region 13q11. Genomics. 1999;62(2):156-64. https://doi.org/10.1006/geno.1999.6003

5. Engert JC, Bérubé P, Mercier J, Doré C, Lepage P, Ge B et al. ARSACS, a spastic ataxia common in northeastern Québec, is caused by mutations in a new gene encoding an 11.5-kb ORF. Nat Genet. 2000;24(2):120-5. https://doi.org/10.1038/72769

6. Parfitt DA, Michael GJ, Vermeulen EG, Prodromou NV, Webb TR, Gallo JM et al. The ataxia protein sacsin is a functional co-chaperone that protects against polyglutamine-expanded ataxin-1. Hum Mol Genet. 2009;18(9):1556-65. https://doi.org/10.1093/hmg/ddp067

7. Bouhlal Y, Amouri R, El Euch-Fayeche G, Hentati F. Autosomal recessive spastic ataxia of Charlevoix-Saguenay: an overview. Parkinsonism Relat Disord. 2011;17(6):418-22. https://doi.org/10.1016/j.parkreldis.2011.03.005

8. Gerwig M, Krüger S, Kreuz FR, Kreis S, Gizewski ER, Timmann D. Characteristic MRI and funduscopic findings help diagnose ARSACS outside Quebec. Neurology. 2010;75(23):2133. https://doi.org/10.1212/WNL.0b013e318200d7f8

9. Richter AM, Ozgul RK, Poisson VC, Topaloglu H. Private SACS mutations in autosomal recessive spastic ataxia of Charlevoix-Saguenay (ARSACS) families from Turkey. Neurogenetics. 2004;5(3):165-70. https://doi.org/10.1007/s10048-004-0179-y

10. Grieco GS, Malandrini A, Comanducci G, Leuzzi V, Valoppi M, Tessa A et al. Novel SACS mutations in autosomal recessive spastic ataxia of Charlevoix-Saguenay type. Neurology. 2004;62(1):103-6. https://doi.org/10.1212/01.WNL.0000104491.66816.77

11. Criscuolo C, Saccà F, De Michele G, Mancini P, Combarros $\mathrm{O}$, Infante $\mathrm{J}$ et al. Novel mutation of SACS gene in a Spanish family with autosomal recessive spastic ataxia. Mov Disord. 2005;20(10):1358-61. https://doi.org/10.1002/mds.20579

12. Bouhlal Y, El Euch-Fayeche G, Hentati F, Amouri R. A novel SACS gene mutation in a Tunisian family. J Mol Neurosci. 2009;39(3):333-6. https://doi.org/10.1007/s12031-009-9212-9

13. Takiyama Y. Autosomal recessive spastic ataxia of Charlevoix-Saguenay. Neuropathology. 2006;26(4):368-35. https://doi.org/10.1111/j.1440-1789.2006.00664.x

14. Vermeer S, Meijer RP, Pijl BJ, Timmermans J, Cruysberg JR, Bos MM et al. ARSACS in the Dutch population: a frequent cause of early-onset cerebellar ataxia. Neurogenetics. 2008;9(3):207-14. https://doi.org/10.1007/s10048-008-0131-7

15. Baets J, Deconinck T, Smets K, Goossens D, Van den Bergh P, Dahan Ket al. Mutations in SACS cause atypical and late-onset forms of ARSACS. Neurology. 2010;75(13):1181-8. https://doi.org/10.1212/WNL.0b013e3181f4d86c
16. Martin MH, Bouchard JP, Sylvain M, St-Onge O, Truchon S. Autosomal recessive spastic ataxia of Charlevoix-Saguenay: a report of MR imaging in 5 patients. AJNR Am J Neuroradiol. 2007;28(8):1606-8. https://doi.org/10.3174/ajnr.A0603

17. Shimazaki H, Takiyama Y, Honda J, Sakoe K, Namekawa M, Tsugawa $J$ et al. Middle cerebellar peduncles and Pontine T2 hypointensities in ARSACS.J Neuroimaging. 2013;23(1):82-5. https://doi.org/10.1111/j.1552-6569.2011.00647.x

18. Richards S, Aziz N, Bale S, Bick D, Das S, Gastier-Foster J et al. Standards and guidelines for the interpretation of sequence variants: a joint consensus recommendation of the American College of Medical Genetics and Genomics and the Association for Molecular Pathology. Genet Med. 2015;17(5):405-24. https://doi.org/10.1038/gim.2015.30

19. De Braekeleer M, Giasson F, Mathieu J, Roy M, Bouchard JP, Morgan K. Genetic epidemiology of autosomal recessive spastic ataxia of Charlevoix-Saguenay in northeastern Quebec. Genet Epidemiol. 1993;10(1):17-25. https://doi.org/10.1002/gepi.1370100103

20. Thiffault I, Dicaire MJ, Tetreault M, Huang KN, Demers-Lamarche J, Bernard G et al. Diversity of ARSACS mutations in French-Canadians. Can J Neurol Sci. 2013;40(1):61-6. https://doi.org/10.1017/S0317167100012968

21. Hara K, Onodera O, Endo M, Kondo H, Shiota H, Miki Ket al. Sacsin-related autosomal recessive ataxia without prominent retinal myelinated fibers in Japan. Mov Disord. 2005;20(3):380-2. https://doi.org/10.1002/mds.20315

22. Vingolo EM, Di Fabio R, Salvatore S, Grieco G, Bertini E, Leuzzi V et al. Myelinated retinal fibers in autosomal recessive spastic ataxia of Charlevoix-Saguenay. Eur J Neurol. 2011;18(9):1187-90. https://doi.org/10.1111/j.1468-1331.2010.03335.x

23. Desserre J, Devos D, Sautière BG, Debruyne P, Santorelli FM, Vuillaume I et al. Thickening of peripapillar retinal fibers for the diagnosis of autosomal recessive spastic ataxia of Charlevoix-Saguenay. Cerebellum. 2011;10(4):758-62. https://doi.org/10.1007/s12311-011-0286-x

24. Synofzik M, Soehn AS, Gburek-Augustat J, Schicks J, Karle KN, Schüle R et al. Autosomal recessive spastic ataxia of Charlevoix Saguenay (ARSACS): expanding the genetic, clinical and imaging spectrum. Orphanet J Rare Dis. 2013;8(1):41-53. https://doi.org/10.1186/1750-1172-8-41

25. Pilliod J, Moutton S, Lavie J, Maurat E, Hubert C, Bellance $\mathrm{N}$ et al. New practical definitions for the diagnosis of autosomal recessive spastic ataxia of Charlevoix-Saguenay. Ann Neurol. 2015;78(6):871-86. https://doi.org/10.1002/ana.24509

26. Schüle R, Wiethoff S, Martus P, Karle KN, Otto S, Klebe S et al. Hereditary spastic paraplegia: clinicogenetic lessons from 608 patients. Ann Neurol. 2016;79(4):646-58. https://doi.org/10.1002/ana.24611

27. Pedroso JL, Braga-Neto P, Abrahão A, Rivero RL, Abdalla C, Abdala $\mathrm{N}$ et al. Autosomal recessive spastic ataxia of Charlevoix-Saguenay (ARSACS): typical clinical and neuroimaging features in a Brazilian family. Arq Neuropsiquiatr. 2011;69(2B):288-91. https://doi.org/10.1590/S0004-282X2011000300004

28. Anheim M, Tranchant C, Koenig M. The autosomal recessive cerebellar ataxias. N Engl J Med. 2012;366(7):636-46. https://doi.org/10.1056/NEJMra1006610 